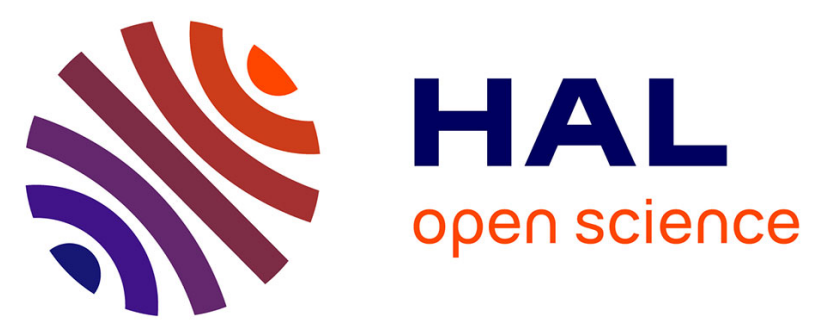

\title{
PLM 4.0 - Recalibrating Product Development and Management for the Era of Internet of Everything (IoE)
}

Julius Golovatchev, Prodip Chatterjee, Florian Kraus, Roger Schüssl

\section{To cite this version:}

Julius Golovatchev, Prodip Chatterjee, Florian Kraus, Roger Schüssl. PLM 4.0 - Recalibrating Product Development and Management for the Era of Internet of Everything (IoE). 14th IFIP International Conference on Product Lifecycle Management (PLM), Jul 2017, Seville, Spain. pp.81-91, 10.1007/978-3-319-72905-3_8. hal-01764178

\section{HAL Id: hal-01764178 \\ https://hal.inria.fr/hal-01764178}

Submitted on 11 Apr 2018

HAL is a multi-disciplinary open access archive for the deposit and dissemination of scientific research documents, whether they are published or not. The documents may come from teaching and research institutions in France or abroad, or from public or private research centers.
L'archive ouverte pluridisciplinaire HAL, est destinée au dépôt et à la diffusion de documents scientifiques de niveau recherche, publiés ou non, émanant des établissements d'enseignement et de recherche français ou étrangers, des laboratoires publics ou privés. 
This paper was presented at the IFIP 14th International Conference on Product Lifecycle Management | 9-12 July 2017, Seville, Spain

\title{
PLM 4.0 - Recalibrating Product Development and Management for the Era of Internet of Everything (IoE)
}

\author{
Julius Golovatchev ${ }^{\mathrm{A}}$, Prodip Chatterjee ${ }^{\mathrm{A}}$, Florian Kraus $^{\mathrm{B}}$, Roger Schüssl ${ }^{\mathrm{A}}$ \\ ${ }^{A}$ Detecon International GmbH - Deutsche Telekom Group, Cologne, Germany \\ (julius.golovatchev, prodip.chatterjee, roger.schuessl) @de- \\ tecon.com \\ ${ }^{\mathrm{B}}$ Detecon International GmbH - Deutsche Telekom Group, Munich, Germany \\ florian.krausedetecon.com
}

\begin{abstract}
A rising complexity of products, the ongoing digitization and an accelerated shift of market demands lead to a rapidly rising number of uncertainties in business and technology environments. The Internet of Everything (IoE) offers many potential opportunities and benefits to both service providers and customers. This paper aims to integrate knowledge from diverse fields into a comprehensive, practical approach for development and implementation of products and services using IoE technologies. The research focused especially on the needs and challenges of innovation and product managers who have to find ways to cope with rising uncertainties and the problem of increasingly complex business environments and digitalization. Therefore, this paper presents first learnings that guides practitioners through implementation of industrial IoE and its impact on new product development and management. It gives them guidance on how the companies' IoE projects could be linked with its new product development initiatives.
\end{abstract}

Keywords: Internet of Things· IoT·Internet of Everything $\cdot$ IoE·Product Lifecycle Management·PLM·Product Development·Digital Economy·IoE Platform.

\section{$1 \quad$ Motivation}

The Internet of Everything (as next stage of Internet of Things) and related Smart Products offer companies and their customers many potential benefits. At first glance there may not seem to be much in common between new product development as well as product lifecycle management (PLM) and the Internet of Everything. However, the two subjects are closely related, as the "Things" are products and the devices are products, too.

Since a couple of years the topic of IoE has impact on new product development (NPD) as well as PLM which gains quite some attention from management science [15]. The detailed consideration and research on IoE and its impact on NPD and PLM are still missing. 
This paper was presented at the IFIP 14th International Conference on Product Lifecycle Management | 9-12 July 2017, Seville, Spain

No doubt, IoE is one of the most important trend topics - the term is omnipresent and surprisingly hard to understand for many people in the technology industry and most importantly for many target customers across all verticals (e.g. Automotive, Pharma, FMCG, Energy etc). Perhaps the most significant difference and one focus point of this paper is the importance and power of start-ups who are leveraging the IoE trend and building entirely new products, designed horizontally across industries or tailor made for a certain vertical. The pace of IoE start-ups emerging is significantly high and mainly driven by a dramatic drop in prices for sensors and computing power. In a nutshell, small IoE solutions can have big impact on customers - generating big opportunities but in case of wrong PLM, management will lead eventually to big risks as well [6]. By applying smart PLM for IoE solutions customers can leverage the potential of these new products without risks. Consequently, scholars as well as practitioners call for new perspectives that understand the challenges and opportunities of IoE for product development and management from a management perspective.

The key goals of this research is to understand hot product/service related topics and try to understand how these new emerging IoE players will change PLM especially customers, e.g. large enterprises. To do so, the paper aims at integrating knowledge from the diverse fields into a comprehensive, practical approach for the development and implementation of the products and services using IoE technologies. Furthermore, a more dedicated focus is being set across selected key sectors with strong impact of IoE and PLM in Healthcare, Automotive and the Energy sector.

\section{Research Design}

The research design was in cooperation with companies of Deutsche Telekom Group. In a first step practitioners' experiences were examined in order to assure practical perspectives and problem perceptions were considered sufficiently. Therefore, innovation managers of companies that had already implemented products and services in IoE fields have been inquired through structured expert interviews between June and September 2015 either on-site at the interviewee's office location or via teleconferencing. The interviewees belonged to big industrial companies as well as start-up in the IoE field $(\mathrm{N}=22)$. All experts held a leading position in innovation departments or worked in comparable positions inside their organizations. The focus on members of innovation management departments was chosen to make sure that the interviewees can report from and share insights of different new product development projects in IoE field. Interviews were also conducted with experts from the Healthcare, Automotive and the Energy sector which led to new insights in those sectors. On average, the interviews lasted one hour and have been transcribed, codified and analyzed in order to extract central problems and challenges with IoE and product development.

The results have been consolidated in a second step to develop a comprehensive view that takes into account the identified criteria for the management and implementation of IoE as well as for practitioners' needs and problems. In order to validate the feasibility and practicability of the developed approach, an additional set of interviews with business consultants of Detecon Consulting (Member of Deutsche Telekom Group) was conducted. This way of validation offered the chance to hypothetically check the developed approach with experiences from client projects. 
This paper was presented at the IFIP 14th International Conference on Product Lifecycle Management | 9-12 July 2017, Seville, Spain

Across all analyzed IoE sections, we found strong and clear evidence that start-ups market space is evolving very fast and market participants - analysts, incumbents and start-ups have no doubt that IoE adoption will come and be a big untapped and unleashed market for them. However, the different IoE sections do have different maturity levels.

Looking at customers and PLM we found the most surprising and definitely highest impact development that emerged with IoE solutions the radical shift of PLM amongst vendors (mostly start-ups) and customers (often midsize to large enterprises or cities). Key reason for this is on the one hand the innovativeness and focus of IoE vendors (focusing on a small niche) and on the other hand the impact of IoE generated software and services (especially data analytics) in customers' existing processes. In a nutshell this means that business customers are adopting more and more IoE solutions fitting to their specific needs, which they integrate into their IT infrastructure over time as well as into PLM step-by-step in order to generate more efficiency and improve their products. As these IoE solutions become essential to their business over time they are integrated into customers' PLM process - at this stage they are confronted with likely different PLM set-ups of themselves and their IoE vendors. Customers have to face complexity of managing various IoE vendors - each of them with their hardware, software and service - and have to manage them very carefully and slowly. IoE vendors on the other hand come from the technology sector and use to think in fast and agile environments framed by software releases, adoption to services, functionalities and hardware as well. They have to focus on their own product only and will eventually not be able to consider each of their customer' individual requirements while updating their product. These factors lead to a smart and adaptive PLM framework in order to master tomorrow's IoE landscape.

\section{Internet of Everything and Product Lifecycle Management - Key Definitions and Status Quo}

Detecon defines PLM as a strategic business approach for managing a company's products and services throughout their lifecycle in the most effective and efficient way: starting with the original idea, through the design, marketing and withdrawal phases. There's not an agreed definition of the Internet of Everything [5]. In this paper, we refer to the Internet of Everything (IoE). While IoT relates to the enablement and management of interconnected devices logically associated with physical things, IoE extends this concept beyond things to include people, processes and the data supporting them [7]. In order to proof the status quo of PLM and IoE, to evaluate the impact of IoE on the future product development and management and to develop the new framework and check its feasibility and practicability, an additional set of interviews with business consultants of Detecon Consulting (Member of Deutsche Telekom Group) was conducted alongside interviews with leading enterprises and start-ups across the highlighted four sectors of IoE. This way of validation offered the chance to hypothetically check the developed approach with experiences from client projects.

The key takeaways across several IoE categories are: 
This paper was presented at the IFIP 14th International Conference on Product Lifecycle Management | 9-12 July 2017, Seville, Spain

- IoE and IoT platforms are emerging, driven by large companies. There is a mutual consensus, that in the future customers will orchestrate their IoE solutions on a single platform but it is unclear which platforms will sustain or even dominate.

- Hardware and software need to interplay very well, with a stronger focus going into software and especially data analytics.

- Standardization is low in many areas of IoE due to conflicting consortia and overall the nascent stage of the entire sector.

- Smart factories are in the most advanced stage of that market.

- Artificial Intelligence is playing an increasing role in solution design.

- Enterprise customers start with solutions at small scale in sandbox environments before scaling up and integrating it deeply into existing systems.

- PLM may become a future important element as smart cities emerge [8].

- Digital Twins - designed to improve existing business models - digitally map the real world in the form of physical product instances over the entire product life cycle.

- Start-ups try to position themselves in some areas strongly by partnering with large companies (e.g. Industry 4.0) and others without (e.g. Smart Home).

\section{$4 \quad$ PLM 4.0 in the Era of Internet of Everything (IoE): Management Framework and Application on Use Cases}

In 2010 the authors composed a comprehensive study about PLM in the telecommunication industry for which they analyzed 50 communication service providers with regard to existing PLM structures [9]. In 2014 this PLM approach was adjusted to the Energy and Utilities industry [2]. The results show that an integrated product lifecycle management enables companies to control the increasing complexity such companies are facing. The companies in the Industry 4.0 and during the digital transformation are faced with similar challenges as a result of the increased complexity which makes both problem settings quite analogous [3]. The model proposed in the following section shows that through the structural similarity, problem-solving approaches can be adapted to the current challenges of the Industry 4.0 in the context of IoE implementation (see detailed description of the PLM Framework in) [9]. The dimensions of an integrated PLM and the related design elements were derived from the integrated management principles. The framework encompasses the four dimensions of PLM Strategy, PLM Process, Product Architecture, and PLM IT Architecture and should be used from 
This paper was presented at the IFIP 14th International Conference on Product Lifecycle Management | 9-12 July 2017, Seville, Spain

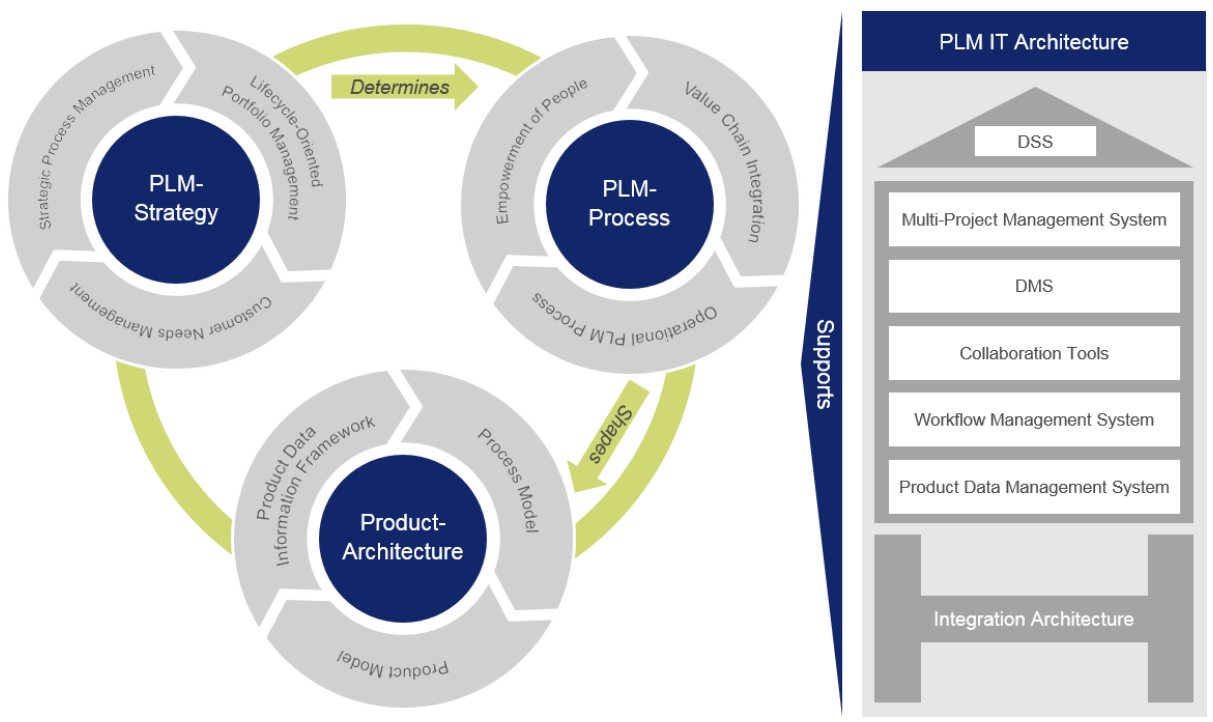

Fig. 1. Proposed Next Generation PLM Framework in the Era of the IoE

companies as an orientation for their processes and products in the future (see Figure 1). The developed PLM framework can serve as a basis for further evaluation of the impact of the IoE on the product development and management. We identified three exemplary use cases in the sectors of Automotive, Healthcare and Energy to outline and assess these challenges and risks.

\subsection{PLM Strategy}

PLM Strategy ensures alignment of products and portfolio with actual and potential market demands, and provides the guiding framework for PLM Process execution. For example, the development of an energy tariff, as incremental innovation, requires a completely different product development process design as the introduction of new innovation complex products and services in the context of e-mobility [10]. IoE brings more and more modules and devices into the game, product lifecycles change and interdependencies between all the components and network infrastructures need to be taken into consideration. Besides that, by designing a PLM Strategy, ever changing market needs have to be accounted. Feedback, demands and expectations are valuable to design individual solutions.

Original Equipment Manufacturer (OEM) in the Automotive industry for example face the challenge to integrate solutions like ProGlove in their smart factories and also in their product development cycles [11]. ProGlove is integrating technology into the natural movement of workers' hands. As a business intelligence solution for production management, it combines RFID, motion tracking, sensors and automated scanning. It is an almost perfect example for how to use IoE technology in the field of manufacturing and logistics. As the vendor's solution is integrated in the production at different OEMs, their requirements have an impact on product enhancements of the IoE device 
This paper was presented at the IFIP 14th International Conference on Product Lifecycle Management | 9-12 July 2017, Seville, Spain

vendor, too. Another example how to use IoE technology in the field of manufacturing is via a Digital Twin. A Digital Twin depicts real products or systems digitally to constitute an application of its physical twin and predicts traits and performance over the whole lifecycle. By using live data (e.g. sensor data) it enables a realistic replication of the physical twin. A Digital Twin offers many opportunities, especially for the Automotive sector. For example, the abrasion of machines or unused capacity could be more easily detected. It allows a faster adaption and implementation and improvement of operations. Moreover, the usage of Digital Twins offers the opportunity to respond very fast to changes. Thus, not only producer requirements can be met but also customer requirements.

IoE devices also found their way in in the Pharma industry, as RFID tags were used to equip drug packages or even eatable devices have been introduced. This groundbreaking technology makes it possible to embed devices in the medication itself and thereby to gather data about medication regiments, health issues, miss-use or even drug black markets. Especially pharma companies and insurance companies would benefit from the usage of such technologies. Pharma companies would benefit in the case of improved drug testing, tracking of side effects and shortened development cycles [12]. Insurance companies would gain deep knowledge by gathered data of how their customers live and take (or not take) their medicine.

In the Energy \& Utilities industry, IoE devices have already been the enabler for innovation in the field of smart grid. The intelligence of these devices is able to transform conventional grids to smart, data driven, grids. The implementation opens up new opportunities towards business models for both existing and also new stakeholders such as utilities and network operators, ICT companies and last but not least the customers [13]. 
This paper was presented at the IFIP 14th International Conference on Product Lifecycle Management | 9-12 July 2017, Seville, Spain

\section{PLM Strategy}

Transparency of

Product \& Portfolio

PLM Governance

PLM Process Variants

Customer Need Management

PLM Reporting \& Controlling

No impact

- Little impact

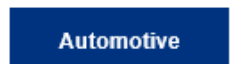

Healthcare

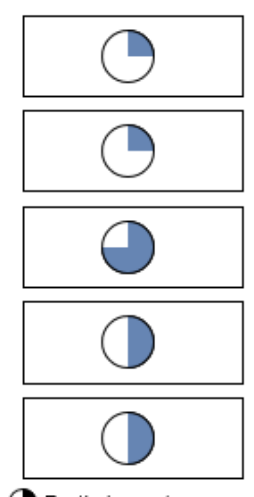

(1) Partly impact

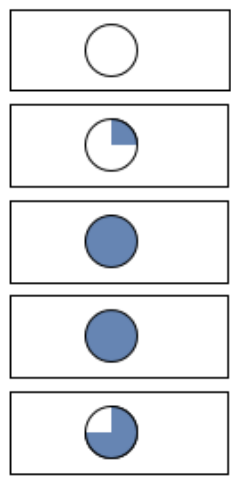

Relevant impact
Energy
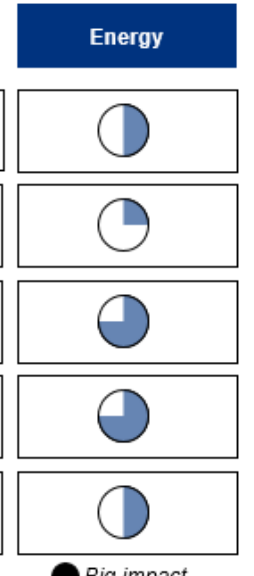

Fig. 2. Proposed Impact of IoE on PLM Strategy

\subsection{PLM Process}

PLM Process facilitates execution of the collaborative process (efficiency goal) and the alignment of activities with the strategic PLM goals of the company (effectiveness goal). Integration and manageability of value-adding partners play a central role, as IoE broadens up opportunities to partner in any possible way. The challenge for the PLM Process is to include all involved partners in the product development process. More and more complex products require standardized processes [10]. The bigger the size and scale of partners in the IoE era, the more challenging it is to align all of them. In times of social media, Big Data and the Internet of Everything, the management of information and innovations of value chain partners become two key success factors.

The interplay of all related parties, e.g. OEM and IoE vendor, becomes even more important in this context. The ProGlove case in the Automotive industry shows, that smart devices not only provide its users with useful information about products, processes and assembling instructions, but is also able to gather information, such as documentation about processes and workflow sequences, and send it back to a central server, in order to be circled back and made useful in the OEM's PLM processes. One of the main challenges for the OEM is to adapt to the fast iterations of the vendors [11]. 
This paper was presented at the IFIP 14th International Conference on Product Lifecycle Management | 9-12 July 2017, Seville, Spain

If one considers a Health \& Pharma industry with smart packages, it is very likely that useful information can be gathered along the product lifecycle and e.g. be used for improving inventory and drug counterfeiting. It also gives pharmacies and retailers a chance to store data (e.g. information for the patients on how to use the drugs) on the chips and provide useful information to the customers.

\section{PLM Process}

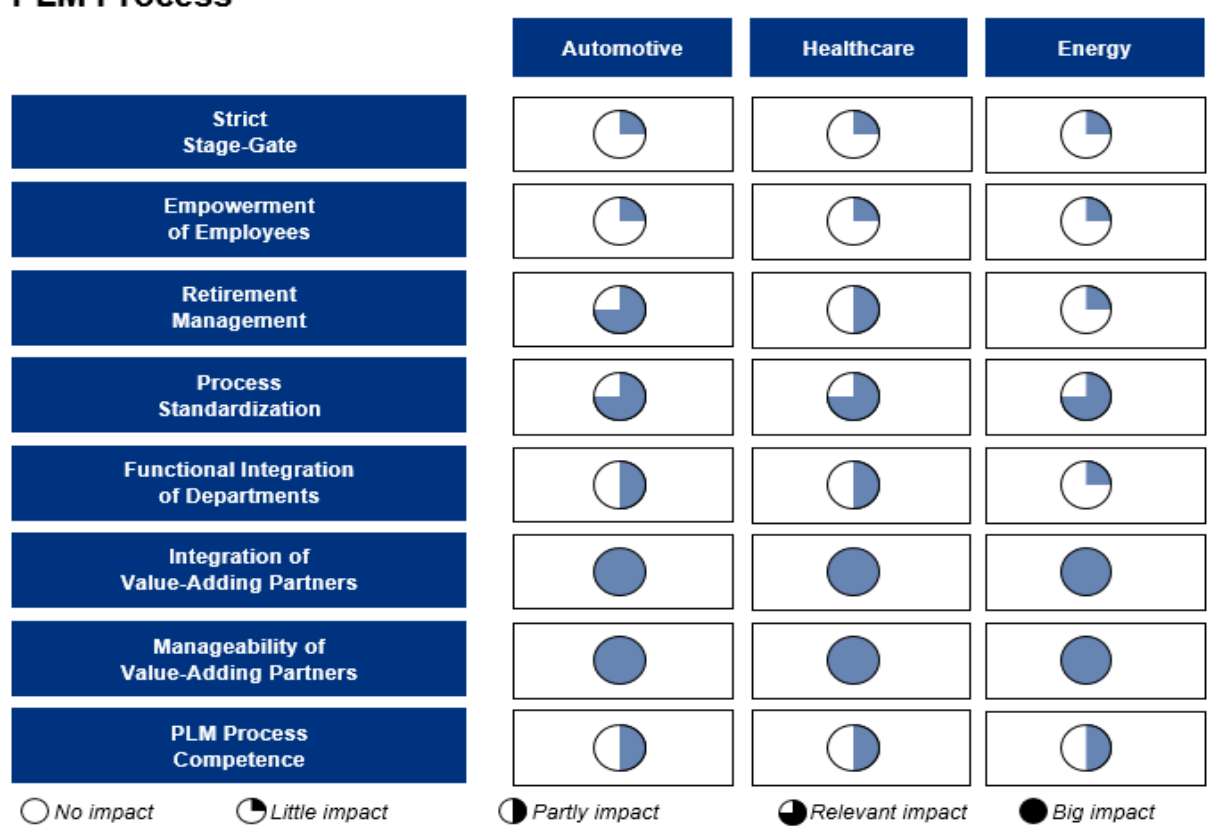

Fig. 3. Proposed Impact of IoE on PLM Process

\subsection{Product Architecture}

Product Architecture enables product component reusability by defining constraints and rules for decomposing product functionality into modules with product data models. In an environment where products and services are becoming more and more virtualized, product model and product data have to be aligned carefully. Further integration needs be enabled upfront by creating a structured mode based on an information network. Implementing a Product Architecture that respects these aspects is a major challenge [1].

One of the most dramatic impact across all three analyzed sectors is the impact of product data to be aligned with product model. The core and heart of the IoE value addition lies in generation of data which was never measured before in real time, mainly complementing the core products. For an Automotive OEM it means that ProGlove's data will not change the car from the ground up, but rather influence the manufacturing process and certain car features. For Healthcare it means that data generated out of 
This paper was presented at the IFIP 14th International Conference on Product Lifecycle Management | 9-12 July 2017, Seville, Spain

fitness bands influence the way obesity treatment is being done. Energy companies change their energy mix in real time due to smart meters. All follow same principles.

\section{Product Architecture}

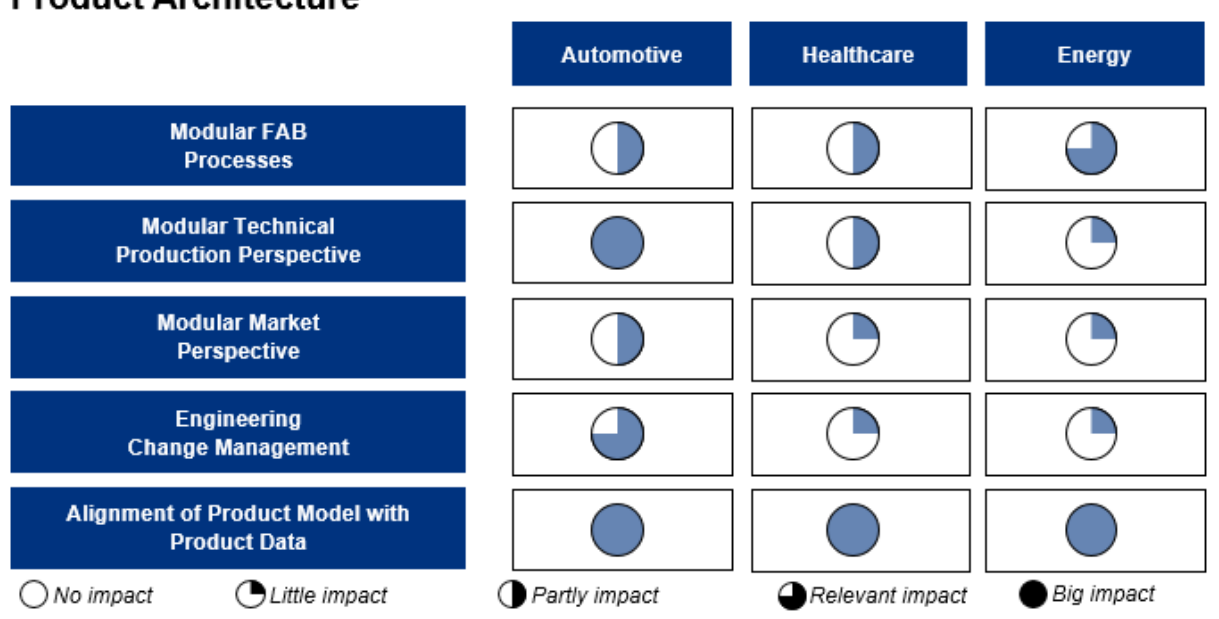

Fig. 4. Proposed Impact of IoE on Product Architecture

\subsection{PLM IT Architecture}

PLM IT Architecture increases PLM process execution efficiency by providing a bestof-breed framework of IT components that ensures an optimal IT-to-process fit.

Extended Collaboration Tools need to ensure a continuous data provisioning for controlling and product portfolio purposes, both within the own organization, as well as with outside partners. Efficient and intelligent data management is a basic requirement to benefit from the power of IoT at all. Unstructured data is useless data, thus data management needs to cover data visibility and role-based access to information, harmonized data sources and data consistency, and versioning of product-related data to support availability, accuracy, timeliness and completeness of information towards achieving transparency for making the right decisions at the right time. Tracking and analyzing e.g. financial data from both, a customer-related and product-related point of view is only possible if there is an IT Architecture in place that supports application integration. Not only financial systems, but also Customer Relationship Management (CRM), Operation Support Systems (OSS) and Business Support Systems (BSS) need to be fully integrated [6].

Across all three verticals, PLM IT Architecture is probably one of the most challenging parts, mainly due to the strong implications and risks while implementing an IoE solution (e.g. from a start-up) at full scale especially in terms of data management. The key strategies here are piloting and sandboxing in the beginning and trial phase of 
This paper was presented at the IFIP 14th International Conference on Product Lifecycle Management | 9-12 July 2017, Seville, Spain

the IoE product followed by a cautious step-by-step integration after successful pilot. In Automotive more data can lead to changed optimization processes in engineering but also aftersales. Healthcare companies especially leverage IoE sensor data in its R\&D phase when integrating additional data into their modelling and simulation tools. For utility companies, smart products can have major influence even on core elements of their ERP system (e.g. procurement and billing due to smart gateways and grids) [4]. The developed PLM Framework can serve as a basis for further evaluation of the impact of the IoE on the product development and management.

\section{PLM IT Architecture}

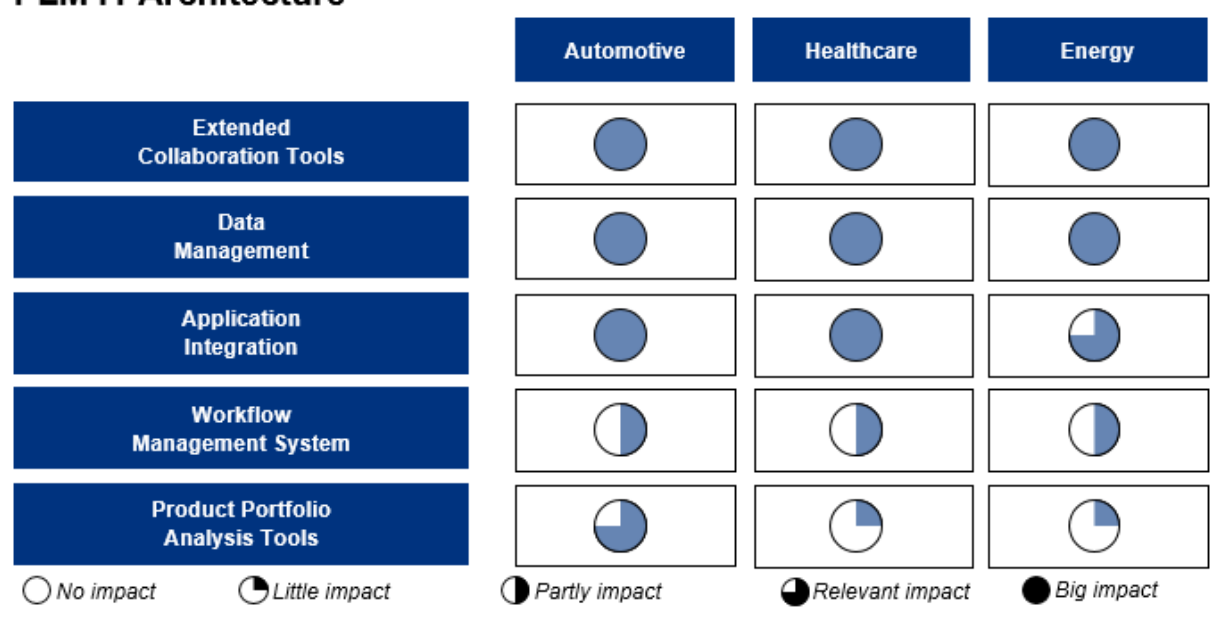

Fig. 5. Proposed Impact of IoE on PLM IT Architecture

\section{$5 \quad$ Conclusion and Outlook}

The key goal of this paper is to understand hot product- and service-related topics, business- and go-to-market models of the participants inside the IoE market and trying to understand how these new emerging IoE players will change the PLM especially customers, e.g. large enterprises who are picking up to adapt and test these new IoE solutions - with many of these enterprises having not dealt with start-ups as suppliers for key product areas that have substantial effect on their business (processes).

The research results show that it is generally feasible to establish a general management perspective on development of products and services within IoE. Furthermore, new areas of research could have been identified by focusing on practitioners' challenges within IoE and new product development that have not been investigated by recent literature. Furthermore, a future outlook across selected key sectors (with IoE product related issues in Automotive, Healthcare, and Energy) is also a focus of this analysis.

The research focused especially on the needs and challenges of innovation and product managers who have to find ways to cope with rising uncertainties and the problem of increasingly complex business environments and digitalization. Therefore, this paper 
This paper was presented at the IFIP 14th International Conference on Product Lifecycle Management | 9-12 July 2017, Seville, Spain

presents first learnings that guides practitioners through implementation of industrial IoE and its impact on new product development and management. It gives them guidance on how the company's IoE project could be linked with its new product development initiatives. Ideally, managers are able to achieve improved product market fit, save costs due to early problem identification and enjoy a wide range of communicative advantages by using the results of the paper. 
This paper was presented at the IFIP 14th International Conference on Product Lifecycle Management | 9-12 July 2017, Seville, Spain

\section{References and Notes}

1. Budde, O., Golovatchev, J. (2011). Descriptive Service Product Architecture for Communication Service Provider. In: Hesselbach, J., Herrmann, C., Functional Thinking for Value Creation, Springer Berlin-Heidelberg, pp. 213-218.

2. Budde, O., Golovatchev, J. (2014). Produkte des intelligenten Markts. In: Aichele, C., Doleski, O. D. (Hrsg.). Smart Market, Springer Fachmedien, Wiesbaden, pp. 593620.

3. Golovatchev, J., Budde, O. (2013). Complexity measurement metric for innovation implementation and product management. In: International Journal of Technology Marketing, 8. Jg. (1), pp. 82-98.

4. Golovatchev, J., Budde, O. (2016a). PLM Framework for the Development and Management Smart Energy Products. In: A. Bouras et al. (Eds.): Product Lifecycle Management in the Era of Internet of Everything, PLM 2015 IFIP AICT 467, pp. 698-707.

5. Stark, J. (2015). Product Lifecycle Management: Paradigm for 21st Century Product Realisation, 3rd Edition, Volume 1.

6. Golovatchev, J., Kraus, F., Schüssl, R. (2016b). The Tsunami Breaker. Smart PLM 4.0 to Tame Internet of Things. In: Detecon Management Report, No. 2, pp. 8-16.

7. IEEE, 2015. Towards a Definition of the Internet of Things (IoT).

8. Golovatchev, J., Felsmann, M. (2017). Modulare und durchgängige Produktmodelle als Erfolgsfaktor zur Bedienung einer Omni-Channel-Architektur - PLM 4.0. In: Doleski, O. D. (Hrsg.), Herausforderung Utility 4.0. Springer Fachmedien, Wiesbaden, pp. 199-210.

9. Golovatchev,J., et al. (2010). Next Generation Telco Product Lifecycle Management. How to Overcome Complexity in Product Management by Implementing Best-Practice PLM. Detecon, Bonn, Online: www.detecon.com/PLM.

10. Golovatchev, J., Budde, O., Hong, C. (2010b). Integrated PLM-process-approach for the development and management of telecommunications products in a multi-lifecycle environment. In: International Journal of Manufacturing Technology and Management, 19. Jg. (3), pp. 224-23.

11. ProGlove, as of $13^{\text {th }}$ March 2017: Webpage. http://www.proglove.de/.

12. Connect webpage, as of $13^{\text {th }}$ March 2017. http://www.connect.de/ratgeber/wearables-industrie-medizin-fallbespiele-bmw-sap-3120436.html. 
This paper was presented at the IFIP 14th International Conference on Product Lifecycle Management | 9-12 July 2017, Seville, Spain

13. Jonker, W. (2012). Smart Energy Systems in EIT ICT Labs - A European Perspective. 